\title{
Expression Levels of TLRs Involved in Viral Recognition in PBMCs from HIV-1-Infected Patients Failing Antiretroviral Therapy
}

\author{
Carolina Scagnolari $^{a}$ Carla Selvaggi ${ }^{a} \quad$ Luisa Chiavuzzo $^{a}$ Teresa Carbone ${ }^{a}$ \\ Lorenzo Zaffiri $^{b}$ Gabriella d'Ettorre ${ }^{b}$ Enrico Girardic Ombretta Turriziania \\ Vincenzo Vullo ${ }^{b}$ Guido Antonellia \\ ${ }^{a}$ Virology Section, Department of Experimental Medicine, and ${ }^{b}$ Department of Infectious Diseases, \\ Policlinico Umberto I, Sapienza University, and ' National Institute for Infectious Diseases L. Spallanzani, Rome, Italy
}

\section{Key Words}

Human immunodeficiency virus $\cdot$ Pathogenesis $\cdot$ Pattern

recognition receptors $\cdot$ Toll-like receptors $\cdot$ Viremia

\begin{abstract}
Objective: The aim of this study was to evaluate whether gene expression of Toll-like receptor (TLR)-3, TLR4, TLR7 and TLR9 was impaired in patients with chronic HIV-1 infection who were failing to respond to antiretroviral therapy. Methods: Transcripts encoding TLRs were assayed by quantitative real time RT-PCR on peripheral blood mononuclear cells derived from patients with HIV-1 infection who were responding or not responding to antiretroviral therapy and healthy control subjects. Results: Chronic HIV-1-infected patients who failed to respond to therapy showed reduced expression of TLRs 3, 4 and 9, together with increased expression of TLR7, as compared to healthy subjects. Moreover, a trend towards a higher expression of TLR3 and TLR9 was observed in responder patients compared with non-responders. In addition, we found lower levels of TRLs 3, 7 and 9 in patients with high levels of HIV-1 RNA compared to those with lower levels of viremia. Conclusions: These findings demonstrate that in chronic HIV-1-positive patients who were failing to respond to the therapy, there were substantial changes in TLRs expression. This is likely to be an important determinant of the clinical course of HIV-1 infection.
\end{abstract}

Copyright $\odot 2009$ S. Karger AG, Basel

\section{KARGER}

Fax +4161306 1234 E-Mail karger@karger.ch www.karger.com (c) 2009 S. Karger AG, Basel

$0300-5526 / 09 / 0522-0107 \$ 26.00 / 0$

Accessible online at:

www.karger.com/int

\section{Introduction}

Innate immunity is the first line of defense against invading pathogens. The antiviral innate immune response follows the detection of viral components by host pattern recognition receptors [1]. In particular, viral recognition is mediated by different classes of receptors such as the Toll-like receptors (TLRs) and the RIG (retinoic-acid-inducible)-like helicases. TLRs are type I transmembrane receptors which play a critical role in the regulation of innate immunity. To date, the TLR family in humans consists of 10 members. Of these, TLRs 3, 7, 8 and 9 recognize viral nucleic acids on endosomal membrane, whereas TLR4 recognizes both viral components and Gram-negative LPS at the cell surface [2].

TLR3 recognizes double-stranded RNA, and TLR7/8 binds GU-rich single-stranded (ss) RNAs [3, 4]. TLR9 can be activated by cytidine-phosphate-guanosine DNA motifs that are present in bacteria and viruses, whereas TLR4, initially implicated in the recognition of bacterial products, can also detect some viral proteins [5].

After ligand recognition, these members activate their intrinsic signaling pathways and lead to the production of inflammatory cytokines and the activation of antiviral immunity.

There is increasing evidence for a role for TLRs in HIV-1 pathogenesis [6-14]. Schlaepfer et al. [10] showed

Carolina Scagnolari, $\mathrm{PhD}$

Department of Experimental Medicine, Virology Section

Sapienza University of Rome

Viale di Porta Tiburtina 28, IT-00185 Rome (Italy)

Tel. +39 064474 1241, Fax +3906 4474 1236, E-Mail carolina.scagnolari@uniromal.it 
Table 1. Description of HIV-1-infected subjects

\begin{tabular}{lll}
\hline & Non-responders to & Responders to \\
& HAART $(\mathrm{n}=46)$ & HAART $(\mathrm{n}=10)$ \\
\hline Median age (range), years & $44(26-63)$ & $43(31-64)$ \\
Males/females, $\mathrm{n}$ & $29 / 17$ & $5 / 5$ \\
HIV-1 subtype & $\mathrm{B}$ & $\mathrm{B}$ \\
Median CD4 T cell count (range), $\mathrm{n} / \mathrm{mm}^{3}$ & $384(2-1,451)$ & $500(250-980)$ \\
Median viral load (range), copies/ml & $19,800(60-500,000)$ & $<50$ \\
Median duration of HAART (range), years & $12(6-18)$ & $7(3-13)$ \\
Patients with opportunistic infection, $\mathrm{n}$ & 0 & 0 \\
Patients not receiving HAART, $\mathrm{n}$ & 12 & 0 \\
Specific drugs taken at the time of analysis, $\%$ & & \\
Emtricitabine & 0 & 10 \\
Lamivudine & 76.4 & 100 \\
Stavudine & 35.2 & 10 \\
Zidovudine & 41.1 & 10 \\
Didanosine & 2.9 & 20 \\
Abacavir & 0 & 10 \\
Tenofovir & 23.5 & 30 \\
Nevirapine & 11.7 & 0 \\
Efavirenz & 23.5 & 10 \\
Nelfinavir & 14.7 & 0 \\
Indinavir & 2.9 & 0 \\
Saquinavir & 5.8 & 0 \\
Lopinavir & 17.6 & 40 \\
Atazanavir & 2.9 & 40 \\
Tripanavir & 2.9 & 0 \\
Fosamprenavir & 0 &
\end{tabular}

that TLR7/8 triggering exerts opposing effects in acute versus latent HIV infection. Heggelund et al. [11] found that freshly isolated monocytes from HIV-infected patients display enhanced expression of TLR2. Moreover, it has been reported that a rapid progression of HIV-1 infection was associated with TLR9 polymorphisms [13]. Interestingly, HIV-1 replication is directly dependent on NF- $\kappa$ B, a critical TLR-induced transcription factor that promotes activation of the HIV-1 long terminal repeat [6]. This might be of importance in the mechanism underlying the increased HIV-1 replication and disease progression associated with concomitant and opportunistic infections.

Despite the fact that some TLR family members have a role in HIV-1 pathogenesis, TLR gene expression in peripheral blood mononuclear cells (PBMCs) of HIV1-infected patients has been only marginally investigated.

More studies are needed to gain a better understanding of the key role of TLR in HIV-1 pathogenesis, which could lead to breakthrough discovery.
Hence, considering the importance of TLRs in initiating innate immunity to virus infections, gene expression levels of the TLRs involved in viral recognition (TLR3, TLR4, TLR7 and TLR9) were compared in 46 chronic HIV-1-infected patients, in whom antiretroviral regimens had failed, 10 HIV-1-infected patients defined as responding to highly active antiretroviral therapy (HAART), and 26 healthy donors.

\section{Methods}

Patients

Analyses of TLR gene expression were performed retrospectively on 46 HAART-experienced patients infected by HIV-1 who were failing to respond to antiretroviral therapy. Blood samples from these patients derived from routine genotypic resistance testing at the drug-resistance monitoring service of the Sapienza University of Rome.

Ten HIV-1-positive patients defined as HAART responders were also included in this study. Blood samples from these patients were collected from the Department of Infectious Diseases at the Policlinico Umberto I Hospital for routine HIV-1 viral load testing. 
Demographic and clinical characteristics of HIV-1-infected subjects are summarized in table 1. Descriptions of drug-resistance genotypic data observed in HIV-1-infected subjects who failed to respond to antiretroviral therapy are given in table 2 .

Twenty-six blood donors were also examined as healthy controls. Human PBMCs were isolated from buffy coats of blood donors provided by the blood bank of the Sapienza University of Rome. Blood donors were 18 - to 65 -year-old healthy men and women who were tested negative for HIV and hepatitis B and C viruses. Further exclusion criteria were symptomatic allergies, taking regular prescribed medication or having a diagnosis of any long-term medical condition (e.g. diabetes, hemophilia, cardiovascular disease, anemia, gastrointestinal or neurological diseases).

\section{Isolation of PBMCs}

PBMCs of HIV-1-positive patients and blood donors were separated using Ficoll-Hypaque gradient sedimentation. $5 \times 10^{6}$ PBMCs were collected, pelleted and frozen at $-80^{\circ}$ until required.

\section{TaqMan Quantitative RT-PCR for TLR mRNAs}

The mRNA copy content of TLR genes was measured by a realtime 5' exonuclease RT-PCR assay using the ABI 7000 sequence detector (Applied Biosystems, Monza, Italy). Briefly, total cellular RNA was extracted from the cells using Trizol reagent following the manufacturer's instructions, and was retrotranscribed as previously described [15]. Next the primer pairs and probes [16] were added to the universal PCR master mix (Applied Biosystems) at 300 and $100 \mathrm{nM}$, respectively, in a final volume of $50 \mu \mathrm{l}$. The primers and probes added were as follows. TLR3: forward $5^{\prime}$-ACAACTTAGCACGGCTCTGGA-3', reverse 5'-ACCTCAACTGGGATCTCGTCA-3', probe 5'-ACGCAAACCCTGGTGGTCCCATTTAT-3'. TLR4: forward 5'-AGTTTCCTGCAATGGATCAAGG-3', reverse 5'-CTGCTTATCTGAAGGTGTTGCAC-3', probe 5'-AGGCAGCTCTTGGTGGAAGTTGAACGA-3'. TLR7: forward 5'-TGGAAATTGCCCTCGTTGTT-3', reverse 5'-GTCAGCGCATCAAAAGCATT- ${ }^{\prime}$, probe $5^{\prime}$-CCCATTTCCTTGTGCGCCGTGTAA-3'. TLR9: forward 5'-AGTCAATGGCTCCCAGTTCCT-3', reverse 5'-CGTGAATGAGTGCTCGTGGTA-3', probe 5'-TCTGCAGGTGCTAGACCTGTCCCACAATA-3'. Co-amplification of the $\beta$-glucuronidase gene (Assay-On-Demand, Hs99999908_m1; Applied Biosystems) was used to normalize the amount of total RNA present using the threshold cycle relative quantification according to the supplier's guidelines.

\section{Statistical Analysis}

All results are expressed as median values (range). Differences between patients with chronic HIV-1 infection who were responding or not responding to antiretroviral therapy and healthy controls, in terms of the level of TLRs genes, were compared using the Mann-Whitney test. Spearman's rho coefficient was calculated in order to assess the correlation between the levels of TLRs and CD4 T cell count, viral load and the duration of therapy. The same test was also used to examine whether the mRNA levels of TLRs were correlated among themselves. Difference between patients with high levels of HIV-1 RNA ( $\geq 5$ log HIV-1 RNA copies/ml) and low levels of viremia ( $<5$ log HIV-1 RNA copies/ml) in terms of the levels of TLRs genes were compared using the Mann-Whitney test. Significance was fixed at the 5\% level. The analysis was performed using SPSS v.13.0 for Windows.
Table 2. Resistance mutations in HIV-infected patients

\begin{tabular}{|c|c|c|c|}
\hline $\begin{array}{l}\text { NRTI and NNRTI } \\
\text { mutations }\end{array}$ & $\mathrm{n}(\%)^{1}$ & $\begin{array}{l}\text { PI } \\
\text { mutations }\end{array}$ & n (\%) \\
\hline M41L & $10(21.7)$ & L10I/F/V & $13(28.3)$ \\
\hline E44D & $1(2.2)$ & $\mathrm{I} 13 \mathrm{~V}$ & $1(2.2)$ \\
\hline A62V & $4(8.7)$ & $\mathrm{K} 20 \mathrm{I} / \mathrm{M} / \mathrm{R}$ & $8(17.4)$ \\
\hline K65R & $1(2.2)$ & $\mathrm{D} 30 \mathrm{~N}$ & $1(2.2)$ \\
\hline D67N & $10(21.7)$ & V32I & $1(2.2)$ \\
\hline T69D/N & $3(6.5)$ & $\mathrm{L} 33 \mathrm{~F} / \mathrm{V}$ & $2(4.3)$ \\
\hline K70R & $4(8.7)$ & M36I & $16(34.8)$ \\
\hline L74V & $1(2.2)$ & M46I/L & 7 (15.2) \\
\hline V75I & $2(4.3)$ & I47V & $1(2.2)$ \\
\hline F77L & $1(2.2)$ & G48V & $1(2.2)$ \\
\hline K103N & $6(13.0)$ & $\mathrm{I} 54 \mathrm{~V}$ & $5(10.8)$ \\
\hline V106A & $1(2.2)$ & Q58E & $1(2.2)$ \\
\hline V108I & $2(4.3)$ & L63P & $24(52.1)$ \\
\hline L110I & $2(4.3)$ & $\mathrm{A} 71 \mathrm{I} / \mathrm{V} / \mathrm{T}$ & $10(2.2)$ \\
\hline Y115F & $1(2.2)$ & G73S & $3(6.5)$ \\
\hline F116Y & $2(4.3)$ & V77E & $1(2.2)$ \\
\hline V118I & $9(19.6)$ & V82A/T & 5 (10.9) \\
\hline Q151M & $2(4.3)$ & I84V & $1(2.2)$ \\
\hline V179D/E & $2(4.3)$ & L90M & $8(17.4)$ \\
\hline Y181C & $5(10.8)$ & K20I & $2(4.3)$ \\
\hline M184I/V & $17(37.0)$ & & \\
\hline Y118L & $1(2.2)$ & & \\
\hline G190A & $6(13.0)$ & & \\
\hline L210W & $9(19.6)$ & & \\
\hline $\mathrm{T} 215 \mathrm{~F} / \mathrm{Y}$ & $12(26.1)$ & & \\
\hline K219Q/E & $8(17.4)$ & & \\
\hline $\mathrm{M} 230 \mathrm{~L}$ & $1(2.2)$ & & \\
\hline Average number of DRM & 4.55 & & 5.55 \\
\hline
\end{tabular}

Table shows HIV reverse transcriptase and protease mutations conferring levels of antiretroviral drug resistance in HIV-1-infected patients who failed to respond to HAART. HIV genotyping was performed on plasma using TruGene HIV-1 genotyping kit (Bayer Health Care LLC, Tarrytown, N.Y., USA) in accordance with the manufacturer's instructions. DRM $=$ Drug resistance mutations.

${ }^{1}$ Percent of total number of HIV-infected patients.

\section{Results}

\section{Expression Levels of TLRs during Chronic HIV-1 \\ Infection}

PBMCs from 46 HAART-experienced patients, in whom therapeutic regimens had failed, were examined for TLR3, TLR4, TLR7 and TLR9 gene expression. The same analysis was also conducted on PBMCs from 10 HIV-1-positive patients defined as HAART responders and from 26 healthy subjects. 

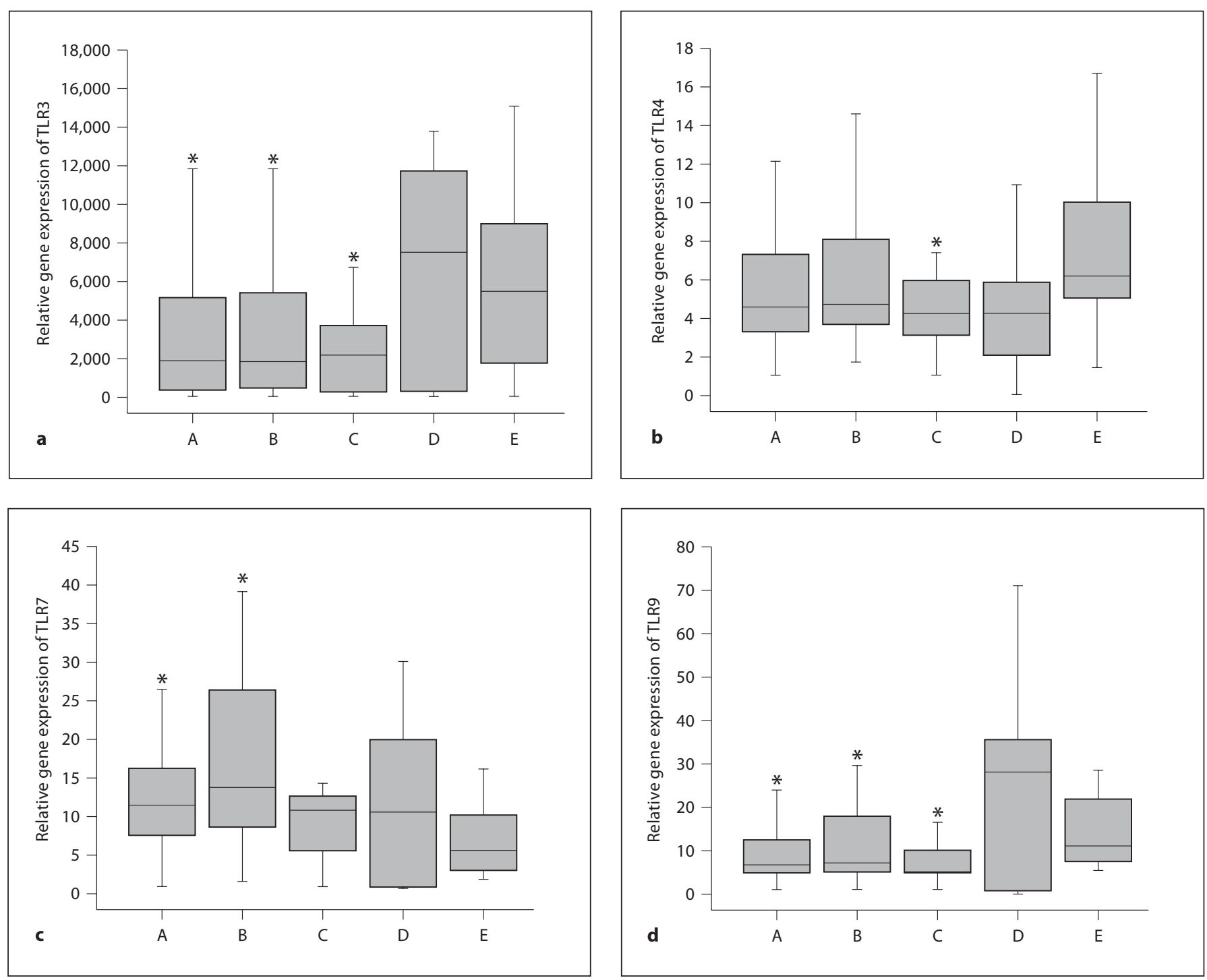

Fig. 1. Expression levels of genes encoding TLR3 (a), TLR4 (b), TLR7 (c) and TLR9 (d) in HIV-1-infected patients responding or not responding to therapy and in healthy subjects. Group A = HIV-1-infected patients who were non-responders to therapy $(n=46)$; group $B=$ non-responding patients who received therapy $(n=34)$; group $\mathrm{C}=$ non-responding patients who interrupted treatment $(\mathrm{n}=12)$; group $\mathrm{D}=\mathrm{HIV}$-1-infected patients who were responders to therapy $(n=10)$; group $\mathrm{E}=$ healthy subjects $(\mathrm{n}=26)$. ${ }^{*} \mathrm{p}<0.05$ vs. group $\mathrm{E}$ (control) by Mann-Whitney test.

The level of expression of all examined TLR transcripts showed high variability among patients with chronic HIV-1 infection and healthy subjects (coefficient of variation $>100 \%$ ).

Nevertheless, reduced levels of TLR3 and TLR9 were found in patients with HIV-1 infection who failed to respond to therapy when compared to healthy subjects ( $\mathrm{p}<0.05$; fig. 1a, d). On the contrary, the values of TLR4 mRNA were found to be lower (although not sig- nificantly, $\mathrm{p}=0.077$ ) in HIV-1-infected patients whose therapeutic regime was failing compared to healthy subjects (fig. 1b). Intriguingly TLR7 mRNA levels were higher in PBMCs of HIV-1-infected patients who were failing to respond to therapy compared to healthy subjects ( $\mathrm{p}<$ 0.05 ; fig. 1c). The same trend was observed when these HIV-1-positive patients were divided into 2 groups: those who received therapy and those who interrupted HAART (fig. 1a-d). 

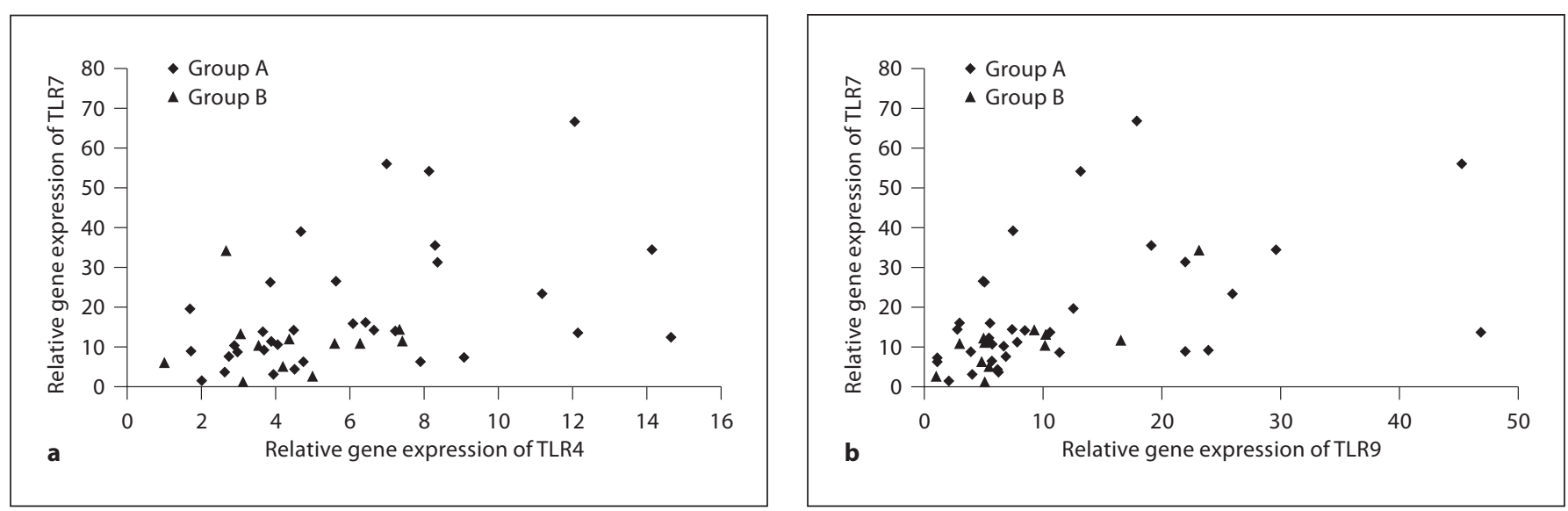

Fig. 2. Correlation between transcript levels of different TLRs in patients with chronic HIV-1 infection who failed to respond to therapy. Group A = HIV-1-infected patients who received therapy ( $\mathrm{n}=34$ ); group B = HIV1-infected patients who interrupted treatment $(n=12)$. a Group A: $r=0.48, p<0.05$; group B: $r=0.15 ; p>0.05$. b group A: $\mathrm{r}=0.48, \mathrm{p}<0.05$; group B: $\mathrm{r}=0.58, \mathrm{p}<0.05$ by Spearman's test.

Table 3. Correlation analysis of TLR mRNA expression in HIV-1-infected patients who failed HAART

\begin{tabular}{|c|c|c|c|c|c|c|}
\hline & \multicolumn{2}{|c|}{ HIV-RNA, copies/ml } & \multicolumn{2}{|c|}{$\mathrm{CD} 4 \mathrm{~T}$ cells, $\mathrm{n} / \mathrm{mm}^{3}$} & \multicolumn{2}{|c|}{ Duration of therapy, years } \\
\hline & rs & $\mathrm{p}$ & rs & $\mathrm{p}$ & rs & $\mathrm{p}$ \\
\hline TLR3 mRNA & 0.16 & 0.27 & 0.03 & 0.80 & -0.05 & 0.80 \\
\hline TLR4 mRNA & 0.09 & 0.54 & -0.15 & 0.38 & 0.22 & 0.28 \\
\hline TLR7 mRNA & 0.18 & 0.22 & -0.08 & 0.59 & 0.10 & 0.63 \\
\hline TLR9 mRNA & 0.24 & 0.87 & 0.21 & 0.15 & -0.05 & 0.97 \\
\hline
\end{tabular}

rs $=$ Rho, Spearman correlation coefficient.

On the other hand, there was no difference in TLR gene expressions between HIV-1-infected patients responding to therapy and healthy subjects $(\mathrm{p}>0.05)$. However, a trend toward higher expression of TLR3, TLR7 and TLR9 was observed in HIV-1-infected patients responding to therapy compared with healthy subjects $(\mathrm{p}>$ 0.05; fig. 1a, c, d). In addition, there was a trend toward lower TLR4 levels in these patients compared to healthy subjects ( $p>0.05$; fig. $1 b$ ).

Finally, we examined whether there were significant differences in transcript levels of TLRs between HIV-1infected patients who were responding or not responding to HAART. As shown in figure 1a and d, TLR3 and TLR9 gene expression levels in non-responders were lower than in responders independent of whether or not they were under therapy at the time of TLR gene expression analysis. However, the expression levels of these genes were not significantly different $(\mathrm{p}>0.05)$. In contrast, expression levels of TLR4 and TLR7 were similar between the 2 groups of subjects ( $\mathrm{p}>0.05$; fig. $1 \mathrm{~b}, \mathrm{c})$.

Factors Influencing Levels of TLRs in Patients Who

Failed to Respond to Therapy

In an attempt to identify the factors influencing TLR gene expression in PBMCs from HIV-1-infected patients whose therapeutic regime was failing, we examined whether the levels of these molecules were correlated among themselves and with the markers of disease progression.

Results revealed significant positive correlations between TLR4 and TLR7 levels and between TLR7 and TLR9 levels in HIV-1-positive patients who were divided into treated and untreated groups (fig. $2 \mathrm{a}, \mathrm{b}$ ). The only exception was the absence of a significant correlation be- 
tween TLR4 and TLR7 in HIV-1-infected patients who interrupted treatment $(\mathrm{r}=0.152, \mathrm{p}>0.05)$.

No significant correlation between the expression of genes encoding TLR3, TLR4, TLR7 and TLR9 and HIV-1 RNA levels or CD4 $\mathrm{T}$ cell count has been found (table 3 ). However, when dividing patients with HIV-1 infection into 2 groups according to HIV-1 RNA levels, we observed a trend toward reduced gene expression of TLR3 [median 2,625.04 (range 1.00-12,944.00) vs. 724.07 (range 200.90-7,486.10), $\mathrm{p}>0.05$ ] and TLR7 [median 12.21 (range 1.00-66.72) vs. 10.33 (range 1.69-35.51), p > 0.05] in patients with levels of viral load $\geq 5 \log$ copies $/ \mathrm{ml}$ compared to those with levels of HIV-1 RNA $<5$ log copies $/ \mathrm{ml}$. A significant reduction in the expression levels of TLR9 [median 3.91 (range 1.04-19.16) vs. 7.64 (range $1.00-46.85), \mathrm{p}<0.05$ ] has been recorded in HIV-1-infected patients with low levels of viremia compared to those with high levels of viremia.

To assess the effect of long-term HAART on TLR gene expression, we examined whether the levels of TLR mRNAs were correlated with the duration of HAART. We found no correlation between transcript levels of TLRs and the length of therapy (table 2).

Moreover, we examined whether there were significant differences in transcript levels of TLRs between HIV-1-infected patients who were receiving or not receiving HAART. There were no significant differences of the TLR3, TLR4, TLR7 and TLR9 expression between the 2 groups of subjects ( $p>0.05$; fig. 1a-d).

\section{Discussion}

These results indicate that TLRs involved in viral recognition were differentially expressed in chronic HIV-1infected patients who, having undergone long-term treatment, were failing to respond to antiretroviral therapy. Specifically, reduced expression of TLRs 3, 4 and 9 was found together with increased expression of TLR7, as compared to healthy subjects. In addition, mRNA levels of TLR3 and TLR9 were reduced in HIV-1-infected patients who failed to respond to the therapy when compared with HIV-1-infected patients defined as responders. However, TLR4 and TLR7 levels were similar in the 2 groups of subjects.

Substantial changes in TLR expression have been observed in patients with different viral infections [17-24]. Therefore, altered gene expression of TLRs 3, 4, 7 and 9 in PBMCs of patients with chronic HIV-1 infection is not surprising and could suggest a potential role for these
TLRs in HIV-1 immunopathogenesis. Our observations are in agreement with the finding that TLR9 expression is impaired during HIV infection [14]. Nicol et al. [25] also reported that HIV-1 infection of macrophages impairs effector functions, including cytokine production and TLR expression. With these findings, we could speculate that HIV could have developed inhibitory mechanisms to subvert TLR-mediated immune responses, as reported for other pathogens [26].

Directly related to this we found a trend toward reduced expression of TLRs 3, 7 and 9 in patients with high levels of HIV-1 RNA compared to those with low levels of viremia or undetectable viral load.

However, one could argue that the reduced expression levels of TLRs 3, 4 and 9 in PBMCs of non-responding patients, which impair the antiviral response, result in increased HIV-1 replication, as previously reported for other viruses [27].

Apart from these speculations, the reasons for the marked changes in TLR gene expression implicated in the recognition of viral components in chronic HIV-1infected patients failing antiretroviral therapy remain unclear and deserve further investigation.

Recently, Lester et al. [28] found that chronic HIV-1 infection is associated with substantial changes in TLR expression which may exacerbate immune activation and pathogenesis. However, they reported that multiple TLRs are increased in chronic untreated HIV-1 infection. This effect is reversible when HIV-1 replication is inhibited after antiretroviral therapy, thus suggesting that HIV-1 replication drives the TLR expression increases in vivo.

The different characteristics of the HIV-1-infected patients who failed to respond to therapy might be the reason for the discrepancy between our results and those of Lester et al. [28]. All of our subjects had been infected with HIV-1 for a long time and had undergone extensive antiretroviral treatment (median 12 years). Thus, we suspect that the altered expression of TLRs could be related to long-term HIV infection, although we did not find any correlation between duration of HAART and levels of TLR expression. Moreover, no differences were observed in TLR expression between HIV-1-positive patients who received therapy and those who interrupted HAART.

Another possible explanation could be that long-term HIV-1 infection is associated with markedly reduced numbers and function of innate immune cells, including plasmacytoid (pDC) and myeloid dendritic cells that have distinct patterns of TLR expression [29-31]. 
Further studies are warranted in order to strengthen the validity of these findings.

In addition, we can speculate that the low mRNA levels of TLRs 3, 4 and 9 in PBMCs of HIV-1-infected patients failing therapy may be associated with a reduced secretion of type I IFN or other inflammatory cytokines that could be responsible for increased susceptibility to opportunistic infections. Indeed, several reports demonstrated that a selective loss of IFN- $\alpha$ production was associated with impairment of accessory cell function in HIV infection [32]. Moreover, it has been reported that a Th1 to Th2 cytokine switch occurs during the course of HIV infection [33]. Unfortunately, the amount of samples was just enough to perform all the experiments shown in the present study, and the above issues could not be addressed.

Interestingly, we observed that TLR7 was highly expressed in PBMCs of HIV-1-infected patients responding or not responding to HAART. These observations are consistent with a previous report, which shows that even after initiating HAART, TLR7 expression is increased in HIV-1-infected patients in comparison to healthy subjects [28]. However, we observed a differential gene expression of TLR7 and TLR9, although they are expressed on the same lymphoid cellular subsets, especially on pDCs, that are highly impaired throughout the course of HIV-1 infection [29-30].

There are several lines of evidence on the specific functional dissociation between TLR7 and TLR9. Martinelli et al. [31] showed that exposure of pDCs to gp120 results in the suppression of activation of these cells. This suppression is specific for TLR9-mediated responses, because TLR7-mediated responses are unaffected by gp 120 . In addition, another report has shown that microbial stimuli differentially affect the expression of their cognate TLR [30]. Specifically, the authors have reported that in cytidine-phosphate-guanosine oligodeoxynucleotide-stimulated pDCs and B cells, TLR9 expression rapidly decreased, as opposed to TLR7, which was upregulated in pDCs.

We confirm that such discrepancy exists, but the reasons for the differential regulations of TLR7 and TLR9 levels in PBMCs of chronic HIV-1-infected patients observed in our study remain unclear.

Potential limitations of our study include the fact that, being a retrospective study, it was performed on total PBMCs. Indeed, we consider that further information on TLR could be derived by analyzing how different human leukocyte populations from HIV-1-infected patients express specific transcript for the TLR. The acquisition of such information is needed to draw definitive conclusions on such issues.

In addition, the limited availability of the samples of PBMCs did not allow us to examine the gene expression of TLR8, which was considered together with TLRs 3, 4, 7 and 9 to be involved in viral recognition and subsequent induction of an antiviral response. Further studies are required to shed light on these critical issues.

In conclusion, this study shows evidence of changes in the expression of several TLR genes implicated in the recognition of viral components in long-term chronic HIV1-infected patients who were failing to respond to antiretroviral therapy. Given the critical role of TLRs in innate immunity and in the initiation of the appropriate adaptive response, the regulation of TLR expression might be an important determinant of the clinical course of HIV-1 infection.

Larger longitudinal studies are required to gain a better understanding of the activation of TLRs during HIV1 infection.

\section{Acknowledgments}

This work was supported by ANLAIDS and by grants to G.A. from Istituto Superiore di Sanità.
References

TLR and HIV Infection
Intervirology 2009;52:107-114 
6 Báfica A, Scanga CA, Schito M, Chaussabel D, Sher A: Influence of coinfecting pathogens on HIV expression: evidence for a role of Toll-like receptors. J Immunol 2004;172: 7229-7234.

7 Sundstrom JB, Little DM, Villinger F, Ellis JE, Ansari AA: Signaling through Toll-like receptors triggers $\mathrm{HIV}-1$ replication in latently infected mast cells. J Immunol 2004; 172:4391-4401.

$>8$ Heggelund L, Flo T, Berg K, Lien E, Mollnes TE, Ueland T, Aukrust P, Espevik T, Frøland SS: Soluble toll-like receptor 2 in HIV infection: association with disease progression. AIDS 2004; 18:2437-2439.

$\checkmark 9$ Sanghavi SK, Reinhart TA: Increased expression of TLR3 in lymph nodes during simian immunodeficiency virus infection: implications for inflammation and immunodeficiency. J Immunol 2005; 175:53145323.

10 Schlaepfer E, Audigé A, Joller H, Speck RF: TLR7/8 triggering exerts opposing effects in acute versus latent HIV infection. J Immunol 2006;176:2888-2895.

-11 Heggelund L, Müller F, Lien E, Yndestad A, Ueland T, Kristiansen KI, Espevik T, Aukrust P, Frøland SS: Increased expression of toll-like receptor 2 on monocytes in HIV infection: possible roles in inflammation and viral replication. Clin Infect Dis 2004;39: 264-269.

-12 Equils O, Salehi KK, Cornataeanu R, Lu D, Singh S, Whittaker K, Baldwin GC: Repeated lipopolysaccharide (LPS) exposure inhibits HIV replication in primary human macrophages. Microbes Infect 2006;8:2469-2476.

$\checkmark 13$ Bochud PY, Hersberger M, Taffé P, Bochud M, Stein CM, Rodrigues SD, Calandra T, Francioli P, Telenti A, Speck RF, Aderem A; the Swiss HIV Cohort Study: Polymorphisms in Toll-like receptor 9 influence the clinical course of HIV-1 infection. AIDS 2007;21:441-446.

14 Ayash-Rashkovsky M, Bentwich Z, Borkow G: TLR9 expression is related to immune activation but is impaired in individuals with chronic immune activation. Int J Biochem Cell Biol 2005;37:2380-2394.
15 Scagnolari C, Trombetti S, Alberelli A, Cicetti S, Bellarosa D, Longo R, Spanò A, Riva E, Clementi M, Antonelli G: The synergistic interaction of interferon types I and II leads to marked reduction in severe acute respiratory syndrome-associated coronavirus replication and increase in the expression of mRNAs for interferon-induced proteins. Intervirology 2007;50:156-160.

16 Nishimura M, Naito S: Tissue-specific mRNA expression profiles of human tolllike receptors and related genes. Biol Pharm Bull 2005;28:886-892.

-17 Monick MM, Yarovinsky TO, Powers LS, Butler NS, Carter AB, Gudmundsson G, Hunninghake GW: Respiratory syncytial virus up-regulates TLR4 and sensitizes airway epithelial cells to endotoxin. J Biol Chem 2003;278:53035-53044.

18 Rudd BD, Burstein E, Duckett CS, Rudd BD Burstein E, Duckett CS, Li X, Lukacs NW: Differential role for TLR3 in respiratory syncytial virus-induced chemokine expression. J Virol 2005;79:3350-3357.

19 Riordan SM, Skinner NA, Kurtovic J, Locarnini S, McIver CJ, Williams R, Visvanathan $\mathrm{K}$ : Toll-like receptor expression in chronic hepatitis C: correlation with pro-inflammatory cytokine levels and liver injury. Inflamm Res 2006;55:279-285.

20 Dolganiuc A, Garcia C, Kodys K, Szabo G: Distinct Toll-like receptor expression in monocytes and $\mathrm{T}$ cells in chronic HCV infection. World J Gastroenterol 2006;12: 1198-1204.

-21 Riordan SM, Skinner N, Kurtovic J, Locarnini S, Visvanathan K: Reduced expression of toll-like receptor 2 on peripheral monocytes in patients with chronic hepatitis B. Clin Vaccine Immunol 2006;13:972-974

22 Machida K, Cheng KT, Sung VM, Levine AM, Foung S, Lai MM: Hepatitis C virus induces toll-like receptor 4 expression, leading to enhanced production of beta interferon and interleukin-6. J Virol 2006;80:866-874.

23 Xu J, Yang Y, Sun J, Ding Y, Su L, Shao C, Jiang B: Expression of Toll-like receptors and their association with cytokine responses in peripheral blood mononuclear cells of children with acute rotavirus diarrhoea. Clin Exp Immunol 2006;144:376-381.

24 Hasan UA, Bates E, Takeshita F, Biliato A, Accardi R, Bouvard V, Mansour M, Vincent I, Gissmann L, Iftner T, Sideri M, Stubenrauch $\mathrm{F}$, Tommasino $\mathrm{M}$ : TLR9 expression and function is abolished by the cervical cancer-associated human papillomavirus type 16. J Immunol 2007;178:3186-3197.
25 Nicol MQ, Mathys JM, Pereira A, Ollington $\mathrm{K}$, Ieong $\mathrm{MH}$, Skolnik PR: Human immunodeficiency virus infection alters tumor necrosis factor alpha production via Toll-like receptor-dependent pathways in alveolar macrophages and U1 cells. J Virol 2008;82: 7790-7798.

26 Thompson AJ, Locarnini SA: Toll-like receptors, RIG-I-like RNA helicases and the antiviral innate immune response. Immunol Cell Biol 2007;85:435-445.

27 Hewson CA, Jardine A, Edwards MR, LazaStanca V, Johnston SL: Toll-like receptor 3 is induced by and mediates antiviral activity against rhinovirus infection of human bronchial epithelial cells. J Virol 2005;79:1227312279.

28 Lester RT, Yao XD, Ball TB, McKinnon LR, Kaul R, Wachihi C, Jaoko W, Plummer FA, Rosenthal KL: Toll-like receptor expression and responsiveness are increased in viraemic HIV-1 infection. AIDS 2008;22:685-694.

29 Muzio M, Bosisio D, Polentarutti N, D’amico G, Stoppacciaro A, Mancinelli R, van't Veer C, Penton-Rol G, Ruco LP, Allavena P, Mantovani A: Differential expression and regulation of toll-like receptors (TLR) in human leukocytes: selective expression of TLR3 in dendritic cells. J Immunol 2000;164:59986004.

30 Hornung V, Rothenfusser S, Britsch S, Krug A, Jahrsdörfer B, Giese T, Endres S, Hartmann G: Quantitative expression of toll-like receptor 1-10 mRNA in cellular subsets of human peripheral blood mononuclear cells and sensitivity to $\mathrm{CpG}$ oligodeoxynucleotides. J Immunol 2002;168:4531-4537.

-31 Martinelli E, Cicala C, Van Ryk D, Goode DJ, Macleod K, Arthos J, Fauci AS: HIV-1 gp120 inhibits TLR9-mediated activation and IFN$\alpha$ secretion in plasmacytoid dendritic cells. Proc Natl Acad Sci USA 2007;104:33963401

32 Herbeuval JP, Shearer GM: HIV-1 immunopathogenesis: how good interferon turns bad. Clin Immunol 2007;123:121-128.

-33 Klein SA, Dobmeyer JM, Dobmeyer TS, Pape M, Ottmann OG, Helm EB, Hoelzer D, Rossol R: Demonstration of the Th1 to Th2 cytokine shift during the course of HIV-1 infection using cytoplasmic cytokine detection on single cell level by flow cytometry. AIDS 1997;11:1111-1118. 